\title{
The Percentage of Family Physicians Attending to Women's Gender-Specific Health Needs Is Declining
}

\author{
Imam M. Xierali, PhD, James C. Puffer, MD, Sebastian T. C. Tong, BA, \\ Andrew W. Bazemore, MD, MPH, and Larry A. Green, MD
}

As the largest and most widely distributed of primary care physicians, family physicians have an important role in providing women's health care, especially in rural and underserved areas. The proportion of family physicians who are attending to women is declining. Policy intervention may be needed to belp family physicians maintain the comprehensiveness of care necessary to address the wide range of medical problems of women they encounter within their practices. (J Am Board Fam Med 2012;25:406-407.)

Access to care is critical for the reproductive and preventive health of women. Gynecologic complaints are among the most common in women of reproductive age and 3 of the top 10 sites of cancer occurrence among the US population are specific to women. ${ }^{1}$ The reported percentage of preventive women's health visits provided by family physicians (FPs) has remained relatively stable, rising from $18.6 \%$ in $1995-1996$ to $20.3 \%$ in 2007. ${ }^{2}$ FPs have an important role in caring for women, particularly in many rural and underserved areas.

We used American Board of Family Medicine (ABFM) diplomate demographic data from 2003 to $2009(\mathrm{n}=7832,9600,7879,8263,9507,9692$,

This article was externally peer reviewed.

Submitted 14 October 2011; revised 7 February 2012; accepted 10 February 2012.

From The Robert Graham Center for Policy Studies in Family Medicine and Primary Care, Washington, DC (IMX, AWB); the American Board of Family Medicine, Lexington, Kentucky (JCP); Boston University School of Medicine, Boston, Massachusetts (STT); and the Department of Family Medicine, University of Colorado at Denver, Aurora (LAG).

Funding: Funding was provided by the American Board of Family Medicine, which contracts annually for health policy/health services research conducted by The Robert Graham Center for studies related to Maintenance of Certification and quality.

Conflict of interest: none declared.

Corresponding author: Imam M. Xierali, The Robert Graham Center for Policy Studies in Family Medicine and Primary Care, 1350 Connecticut Avenue, NW Suite 201, Washington, DC 20036 (E-mail: IXierali@aafp.org). and 9558, respectively) to explore recent trends in the provision of women's health care by FPs. We calculated the proportion of FPs self-reporting actually delivering women's health care across the study years. The percentage of FPs actually attending to the special needs of women has declined steadily, not only in urban areas, but also in rural and primary care Health Professional Shortage Areas (HPSAs) (trend lines, $P<$ .0001 ), from a national average of $73 \%$ in 2003 to $51 \%$ in 2009 (Figure 1).

Given the geographic maldistribution of gynecologists across the nation, FPs play an important role in women's health care. The training and distribution of FPs makes them essential for providing care for American women. Factors leading to the decline are multifaceted. However, although family medicine residents are required to complete at least 1 month of a structured Women's Health curriculum, $40 \%$ of family residency programs were cited for not meeting minimum hourly requirements in this curricular element in 2002. ${ }^{3}$ Without the availability of comprehensive services for women, the mere presence of primary care clinicians will not ensure adequate availability and accessibility of primary care for this population. ${ }^{4}$ Any strategy to ensure high-quality, specialized care for American women now and in the future must address the issue of the declining number of FPs providing this care and the need to increase and enhance comprehensiveness of primary care. 
Figure 1. Declining percent of family physicians provide women's health care. Note that approximately $1 \%$ of cases is excluded annually because of inability to geo-reference addresses. HPSA, Health Professional Shortage Areas. Data from the American Board of Family Medicine Examination Application.

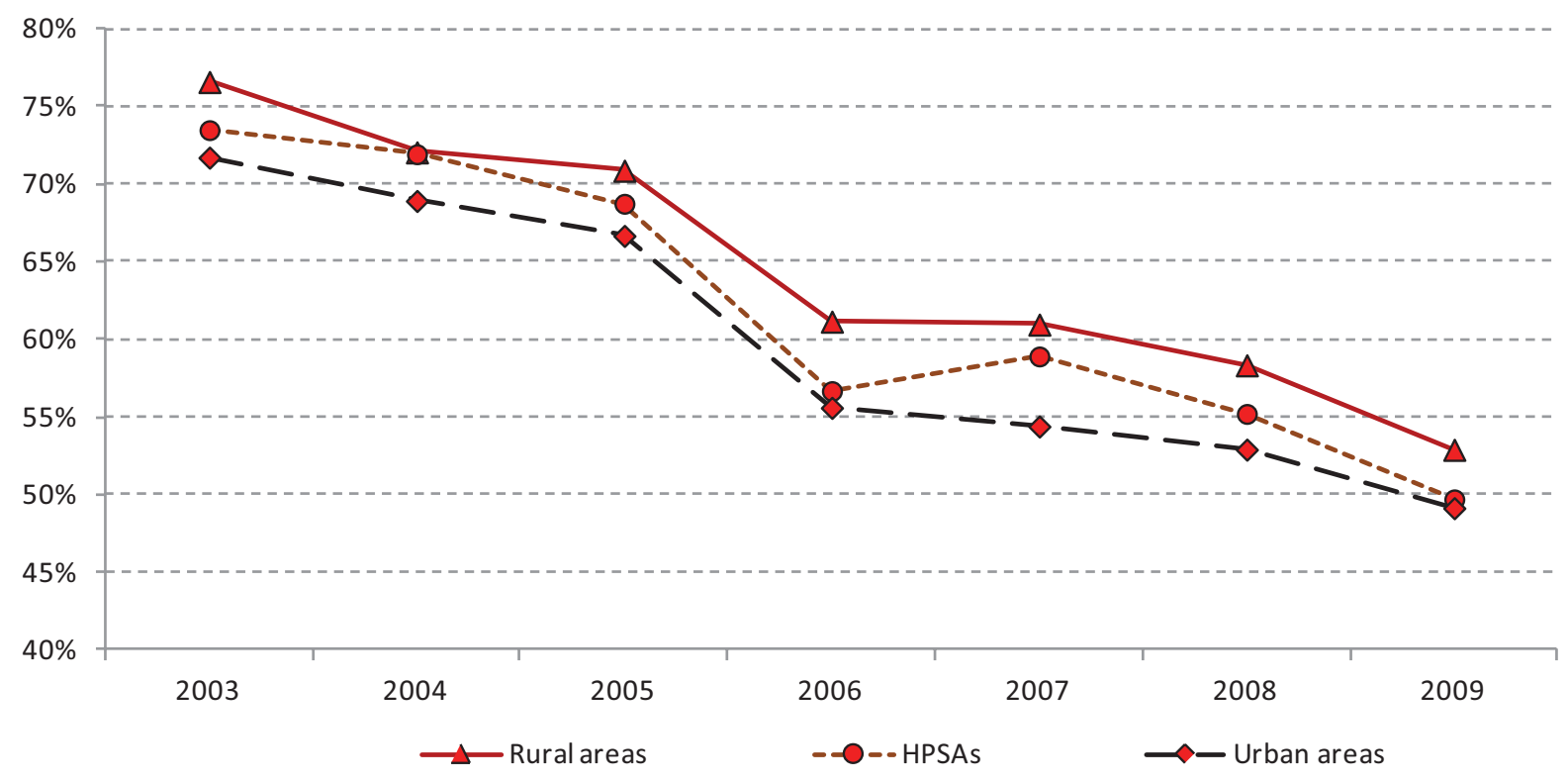

\section{References}

1. U.S. Cancer Statistics Working Group. United States cancer statistics: 1999-2007 incidence and mortality web-based report. 2010. Atlanta, GA: U.S. Department of Health and Human Services, Centers for Disease Control and Prevention and National Cancer Institute. Available from: www.cdc.gov/uscs. Accessed October 8, 2011.
2. Cohen D, Coco A. Trends in the provision of preventive women's health services by family physicians. Fam Med 2011;43:166-71.

3. Pugno PA, Epperly TD. Residency Review Committee for Family Medicine: an analysis of program citations. Fam Med 2005;37:174-7.

4. Starfield B, Shi L. Commentary: primary care and health outcomes: a health services research challenge. Health Serv Res 2007;42:2252-6. 